ras

\title{
Situación laboral de personas viviendo con el virus de inmunodeficiencia humana en la provincia de Buenos Aires
}

\author{
Recibido: 4/1/20 Aceptado: 9/11/20
}

Juan P. Stagnaro ${ }^{1,2}$, Melisa A. Carnabali ${ }^{3}$, Elisa Scaglione ${ }^{4}$, Judith C. Bernstein², Mariana Ceriotto ${ }^{5}$, Tamara Y. Knauer ${ }^{1}$, Juan M. Castelli ${ }^{6}$.

\section{RESUMEN}

Una de las variables para medir la calidad de vida de las personas que viven con el virus de inmunodeficiencia humana $(\mathrm{VIH})$ es el trabajo. El objetivo de este estudio fue comparar, discriminando por género, la situación laboral de personas que viven con VIH en Buenos Aires, Argentina. Es un estudio comparativo realizado en tres hospitales entre abril y julio de 2015. Se evaluó: rango de edad, género, tratamiento antirretroviral, carga viral, personas a cargo, autopercepción del estado de salud, nivel educativo, situación laboral, acceso a beneficio social, comparación entre ingresos con el salario mínimo, oficio. $a=5 \%$ a dos colas. Se realizó test de Mann-Whitney-Wilcoxon y Fisher. Se realizaron 82 encuestas. Un 87,2\% tenían entre 20 y 59 años; relación hombre $(\mathrm{H}) /$ mujer $(\mathrm{M})$ : 1/1; el 84,1\% bajo tratamiento antirretroviral y $67,1 \%$ tenían carga viral indetectable. El 54,9\% con personas a su cargo. La mediana de autopercepción de salud fue de 7,94, sin diferencias entre el sexo $(p=0,35)$. El 48,8\% de los $\mathrm{H}$ y $50 \%$ de las $\mathrm{M}$ tuvieron como máximo 7 años de educación formal. El 17,1\% de los $\mathrm{H}$ y $7,5 \%$ de las $M$ se encontraban desocupadas ( $p=0,03)$; trabajo informal en $65,8 \%$ de $\mathrm{H}$ y $37,5 \%$ de las $\mathrm{M}$, pero el $47,5 \%$ de las $M$ son amas de casa. El 32,9\% de las personas no reciben beneficio social, $20 \%$ de $\mathrm{My} 43,9 \%$ de $\mathrm{H}$ ( $\mathrm{p}=0,03)$. El ingreso de las personas correspondió al $64,8 \%$ del salario mínimo. La situación económica del país cambió, queda ver si la situación laboral también lo hizo.

\author{
'Unidad de Infectología, HZGA “Mi Pueblo" Florencio \\ Varela, Provincia de Buenos Aires. \\ ${ }^{2}$ Centro Universitario de Estudios Microbiológicos y \\ Parasitológicos de la Facultad de Ciencias Médicas, \\ Universidad Nacional de La Plata. \\ ${ }^{3}$ Ministerio de Salud y Desarrollo Social de la República \\ Argentina. \\ ${ }^{4}$ Servicio de Infectología, HIGA “Prof. Dr. Rodolfo Rossi”, La \\ Plata, Provincia de Buenos Aires. \\ ${ }^{5}$ Servicio de Infectología, HZGA “Blas Dubarry”, Mercedes, \\ Provincia de Buenos Aires. \\ ${ }^{6}$ Atención Primaria de la Salud, Municipio de Almirante \\ Brown, Provincia de Buenos Aires.
}

Dirección para la correspondencia: Juan P. Stagnaro, Avenida 60 y 120. Centro Universitario de Estudios Microbiológicos y Parasitológicos de la Facultad de Ciencias Médicas, Universidad Nacional de La Plata. CP: 1900.

Email: jpstagnaro@med.unlp.edu.ar

No se recibió apoyo de ninguna fuente. Ninguno de los autores declara presentar conflictos de intereses en relación a esta publicación Los contenidos del material no han sido publicados anteriormente.

Palabras clave: situación laboral, VIH, desigualdad de género. 


\section{Introducción}

Desde el primer reporte del síndrome de inmunodeficiencia adquirida (SIDA), los avances en el diagnóstico y tratamiento han permitido la mejora en la calidad de vida de las personas que viven con el virus de la inmunodeficiencia humana (PVIH) (1).

En Argentina, la mediana de la edad al diagnóstico es de 32 y 33 años para hombres y mujeres. En los últimos años se ha realizado diagnóstico en personas con mayor nivel de instrucción: entre 2014 y 2016, el 35\% de los varones y el 30,7\% de las mujeres tenían estudios terciarios o superiores; pero uno de cada dos varones y dos de cada tres mujeres no habían completado la educación media $(2,3)$.

La infección por VIH/SIDA conlleva desde su origen aspectos que se vinculan con estigmas que generan sufrimiento en las personas afectadas y sus familias. El VIH/SIDA constituye una amenaza para el mundo del trabajo debido a la posible discriminación de las PVVIH, ya que afecta al sector más productivo de la población (4).

El Centro de Investigación y Formación de la República Argentina y el Centro de Estudios de Formación Sindical resumen los aspectos más relevantes de las condiciones de trabajo en la población general argentina entre 2005 y 2014: la tasa de desocupación pasó del $14,2 \%$ al 7,3\%, siendo mayor en las mujeres que los hombres (6,6\% versus $8,5 \%)$. La brecha de desigualdad de ingresos durante 2014 entre hombres y mujeres era del 34\% menor para estas últimas (5). El valor del salario mínimo vital y móvil (SMVM) según la resolución del Ministerio de Trabajo, Empleo y Seguridad social se pactó en 5588 pesos argentinos en agosto de 2015 (6).

Una de las variables para medir la calidad de vida de las PVVIH es el trabajo: se observó una tendencia de llegar tardíamente al diagnóstico cuando la persona estaba desocupada (67\% en jubilados y $52 \%$ en desocupados que no buscan trabajo) o incluso mayor mortalidad en el grupo de desocupados que no buscan trabajo a los 12 meses de inicio del tratamiento antirretroviral (3).

El impacto del trabajo en la adherencia ha sido evaluado. Las PVVIH empleadas tienen un 39\% más de probabilidad de adherencia óptima a los fármacos antirretrovirales (ARV) que aquellas personas desempleadas. Informantes clave señalaron que la falta de empleo puede impactar negativamente en la adherencia a los ARV. La adherencia óptima es uno de los mejores predictores para lograr una carga viral indetectable, disminuir la progresión de la enfermedad y reducir la letalidad por la enfermedad $(6,7)$.

El objetivo de este trabajo fue comparar la situación laboral de las PVVIH según género en el territorio de la provincia de Buenos Aires.

\section{Materiales y métodos}

Se realizó una encuesta estructurada de diseño cuali-cuantitativa en tres hospitales de la provincia de Buenos Aires entre abril y julio de 2015: Hospital Zonal General de Agudos (HZGA) "Mi Pueblo" de Florencio Varela, el HZGA “Cecilia Grierson” de la localidad de Guernica y el Hospital Interzonal general de Agudos (HIGA) "Prof. Dr. Rodolfo Rossi" de la ciudad de La Plata. Se validó por método Delphi con las primeras diez encuestas.

Se evaluó: rango de edad, nacionalidad, localidad, estado civil, identidad de género, indicación de tratamiento antirretroviral, indetectabilidad de la carga viral, rango de linfocitos T CD4+ al momento de la encuesta, personas a cargo, años viviendo con $\mathrm{VIH}$, autopercepción del estado de salud (definida como valor que una persona le pone a su estado de salud al momento de la encuesta, variable cuantitativa discreta con valores a entre 1 y 10, siendo 1 el valor más bajo), nivel educativo (variable cualitativa ordinal, definida como el máximo nivel educativo adquirido), situación laboral al momento de la encuesta, PVVIH con acceso a beneficio social, ingreso mensual en pesos argentinos al momento de la encuesta, comparación entre el ingreso mensual y el Salario Mínimo Vital y Móvil (SMVM), oficio, tipo de oficio, búsqueda de trabajo seis meses antes de la encuesta, motivos por los cuales no buscó trabajo.

Se recabaron los datos en una planilla de cálculos y se usó el programa SPSS ${ }^{\circ}$ v.19 para su análisis. Se resumieron las variables categóricas en proporciones y las variables cuantitativas en media y desvío estándar. Se estratificó la información en hombres y mujeres. Los datos no recabados se dieron por perdidos para el sistema. Se realizó test de MannWhitney-Wilcoxon para las variables numéricas que no siguen distribución normal y test exacto de Fisher para variables categóricas. Se consideró nivel de significancia estadística a un valor de p menor a 0.05 a dos colas (error tipo1: 5\%).

Se tomó consentimiento informado verbal debido a que no hay intervención sobre la salud de las PVVIH y no hay posibilidad de acceder a información de índole personal de los participantes: no se recabó ni número de documento nacional de identidad, ni número de historia clínica, ni nombre ni apellido. Se realizó la encuesta a pacientes al azar (muestreo no probabilístico). 


\section{Resultados}

Se realizaron 82 encuestas a PVVIH: $37(45,1 \%)$ en el HZGA "Mi Pueblo" de Florencio Varela, 24 (29,3\%) en el HZGA "Cecilia Grierson" de Guernica y 21 (25,6\%) HIGA "Prof. Dr. Rodolfo Rossi" de La Plata. En la Tabla 1 se observa el rango de edad de las PVVIH discriminadas entre género. Todas las personas eran argentinas, excepto dos que eran de nacionalidad paraguaya. El $45,1 \%$ (37) residía en Florencio Varela, 18,3\% (15) en Guernica, 12,2\% (10) en La Plata, y 9,8\% (8) en Ensenada; 3 personas en San Vicente, 2 en Quilmes y en Almirante Brown y el resto en Glew, Ciudad Autónoma de Buenos Aires (CABA), Lanús y Alejandro Korn.

La distribución de género fue similar para hombre y mujer, con un $48,8 \%$ (40) cada uno, y solo una mujer trans (para el análisis se juntó con las mujeres cisgénero). En una PVVIH no se recabó el género, por lo que fue excluida del análisis. El 45,1\% (37) de las PVVIH eran solteras/os, el 22\% (18) convivía en unión de hecho, $13,4 \%$ (11) eran viudas/os, el $9,8 \%$ (8) casadas/os y el resto divorciada/o o separada/o, no encontrando diferencias estadísticamente significativa entre los géneros $(p=0,11)$.

El $84,1 \%$ (69) de las PVVIH se encontraban bajo tratamiento antirretroviral, $77,5 \%$ de los hombres (31) y $92,5 \%$ (37) de las mujeres $(p=0,11)$. El $67,1 \%(55)$ presentaba carga viral indetectable al momento de realizar la encuesta, $70 \%$ (28) de

Tabla 1. Rango de edad. Discriminado por
identidad de género (p=0,79)
\begin{tabular}{|l|c|c|c|c|c|c|}
\hline \\
Rango de edad & \multicolumn{2}{|c|}{ Mujer } & \multicolumn{2}{c|}{ Varón } & \multicolumn{2}{c|}{ Totales } \\
\hline $15-24$ & 4 & 10 & 2 & 4,8 & 7 & 8,5 \\
\hline $25-34$ & 7 & 17,5 & 8 & 19,6 & 16 & 19,5 \\
\hline $35-44$ & 17 & 42,5 & 14 & 34,1 & 31 & 37,8 \\
\hline $45-54$ & 7 & 17,5 & 12 & 29,3 & 19 & 23,2 \\
\hline $55-64$ & 4 & 10 & 3 & 7,3 & 7 & 8,5 \\
\hline Mayor de 65 & 1 & 2,5 & 1 & 2,4 & 2 & 2,4 \\
\hline Total & 40 & 100 & 40 & 100 & 82 & 100 \\
\end{tabular}

los hombres y $67,5 \%(27)$ de las mujeres $(p=1)$. Al analizar el recuento de linfocitos TCD4+, el 20,7\% (17) tenía un recuento de 200 o menos, el 32,9\% (27) entre 201-350, el 12,2\% (10) entre $351-500$ y el $34,1 \%$ (28) tenía 501 o más, siendo estas diferencias estadísticamente no significativas cuando se compararon por género $(p=0,97)$.

El promedio de años viviendo con VIH fue de 8,3 (0-26 años): 8,4 para los hombres y 8,3 para las mujeres $(p=0,52)$. La mediana de la autopercepción de salud fue de 7,9 (2-10), 8 para mujeres y 7,9 para hombres ( $p=0,35)$. El $54,9 \%(45)$ tenían personas a su cargo: $75 \%$ de las mujeres versus el $35 \%$ de los hombres,

\section{Figura 1. Nivel educativo de las PVVIH discriminadas según género. Valor expresado en porcentaje. Diferencia no estadísticamente significativa entre ambos $(p=0,44)$}

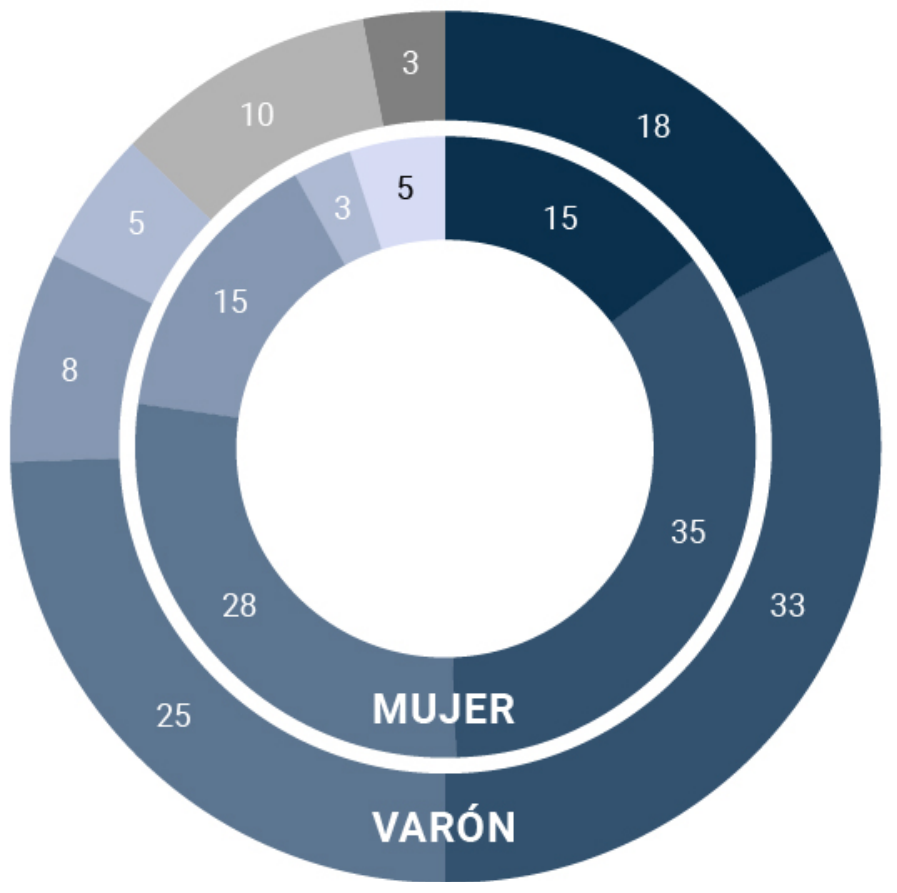

Universitario completo

Universitario incompleto

Terciario incompleto

Terciario completo

Secundario completo

Secundario incompleto

Primario completo

Primario incompleto 


\section{Figura 2. Situación laboral de las personas que viven con el Virus de la Inmunodeficiencia Humana discriminada según género. Valores expresados en porcentaje}

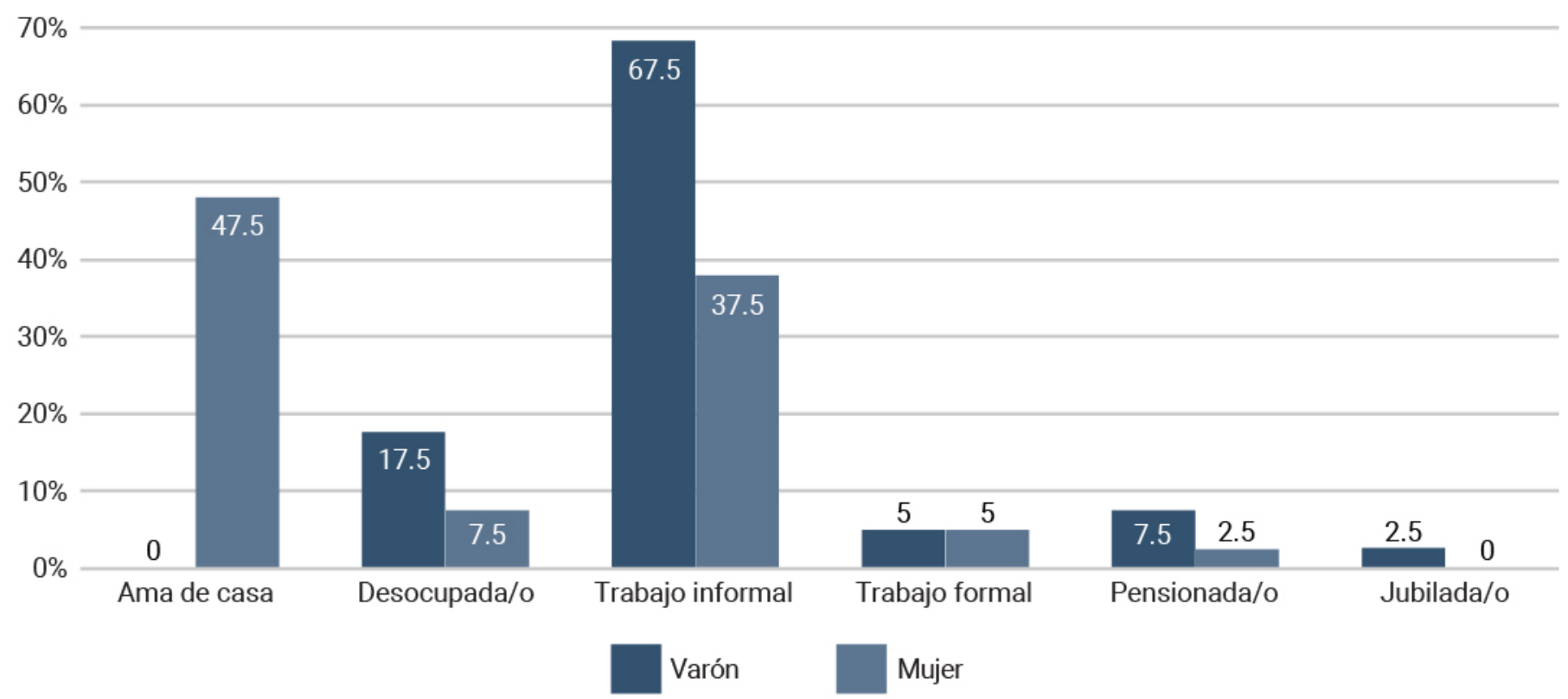

diferencia estadísticamente significativa $(p=0,001)$.

En la Figura 1 se evidencian las diferencias entre el nivel educativo, en la Figura 2 se observa la situación laboral de las $\mathrm{PVVIH}$ discriminadas según género.

El 32,9\% (27) de las PVVIH no recibió ningún beneficio social. Si lo clasificamos según género, el $20 \%(8 / 40)$ de las mujeres y el $43,9 \%$ de los hombres $(18 / 40)$ no recibieron ningún beneficio, diferencia estadísticamente significativa $(p=0,03)$. Las mujeres frecuentemente fueron beneficiarias de la asignación universal por hijo (AUH).

Para un promedio mensual de ingresos en 2015 de 3622 pesos argentinos, los hombres ganaron, en promedio, 162 pesos más que las mujeres (3787 versus 3625 pesos argentinos), diferencia estadísticamente no significativa $(p=0,59)$; esta brecha corresponde a un $5 \%$ de diferencia entre ambos. El valor total corresponde al $64,8 \%$ del SMVM: $67,7 \%$ en hombres y $64,8 \%$ en mujeres.

De las 82 personas evaluadas, el 17,1\% (14) no tenía oficio, lo que corresponde al 9,8\% (4) de los hombres y $27,5 \%$ (11) de las mujeres $(p=0,03)$. En la Tabla 2 se muestran los oficios de las $\mathrm{PVVIH}$, discriminados según género. Se destaca que en los seis meses previos a la encuesta, el $31,7 \%$ (26) de las PVVIH buscaron trabajo: $20 \%$ de las mujeres (8) y $40 \%$ de los hombres (16), no encontrándose diferencia estadísticamente significativa $(p=0,08)$.
En la Figura 3 se describen los motivos por los cuales las PVVIH no buscaron trabajo.

\section{Discusión}

En el análisis inicial de este trabajo observamos como hallazgos relevantes que la muestra, si bien pequeña, no es diferente en

\section{Tabla 2. Oficios de las personas viviendo con VIH discriminado según identidad de género $(p=0,000)$}

\begin{tabular}{l|c|c|c|c|c|c|} 
& \multicolumn{2}{|c|}{ Varón } & \multicolumn{2}{c|}{ Mujer } & \multicolumn{2}{c|}{ Total } \\
Oficios & $\mathbf{N}^{\circ}$ & $\%$ & $\mathbf{N}^{\circ}$ & $\%$ & $\mathbf{N}^{\circ}$ & $\%$ \\
\hline Carpintería & 5 & 12,2 & 0 & 0 & 5 & 6,1 \\
\hline Construcción & 10 & 24,4 & 0 & 0 & 10 & 12,2 \\
\hline Mecánico & 1 & 2,4 & 0 & 0 & 1 & 1,2 \\
\hline Metalúrgica & 2 & 4,9 & 0 & 0 & 2 & 2,4 \\
\hline Textil & 1 & 2,4 & 2 & 5 & 3 & 3,7 \\
\hline Limpieza & 0 & 0 & 5 & 12,5 & 5 & 6,1 \\
\hline Peluquería & 2 & 4,9 & 1 & 2,5 & 3 & 3,7 \\
\hline Empleada & 0 & 0 & 5 & 12,5 & 5 & 6,1 \\
doméstica & 5 & 11,2 & 5 & 12,5 & 10 & 12,2 \\
\hline Gastronomía & 5 & 7,3 & 1 & 2,5 & 4 & 4,9 \\
\hline Vendedor & 3 & 19,5 & 11 & 27,5 & 20 & 24,4
\end{tabular}

Otro: Trabajador/a sexual, maestros jardineros, auxiliar de enfermería/farmacia 


\section{Figura 3. Motivos por los cuales las personas viviendo con el Virus de la Inmunodeficiencia Humana no buscan trabajo discriminado según género. Expresado en porcentaje. Se observa diferencia estadísticamente significativa entre los grupos $(p=0,000)$}

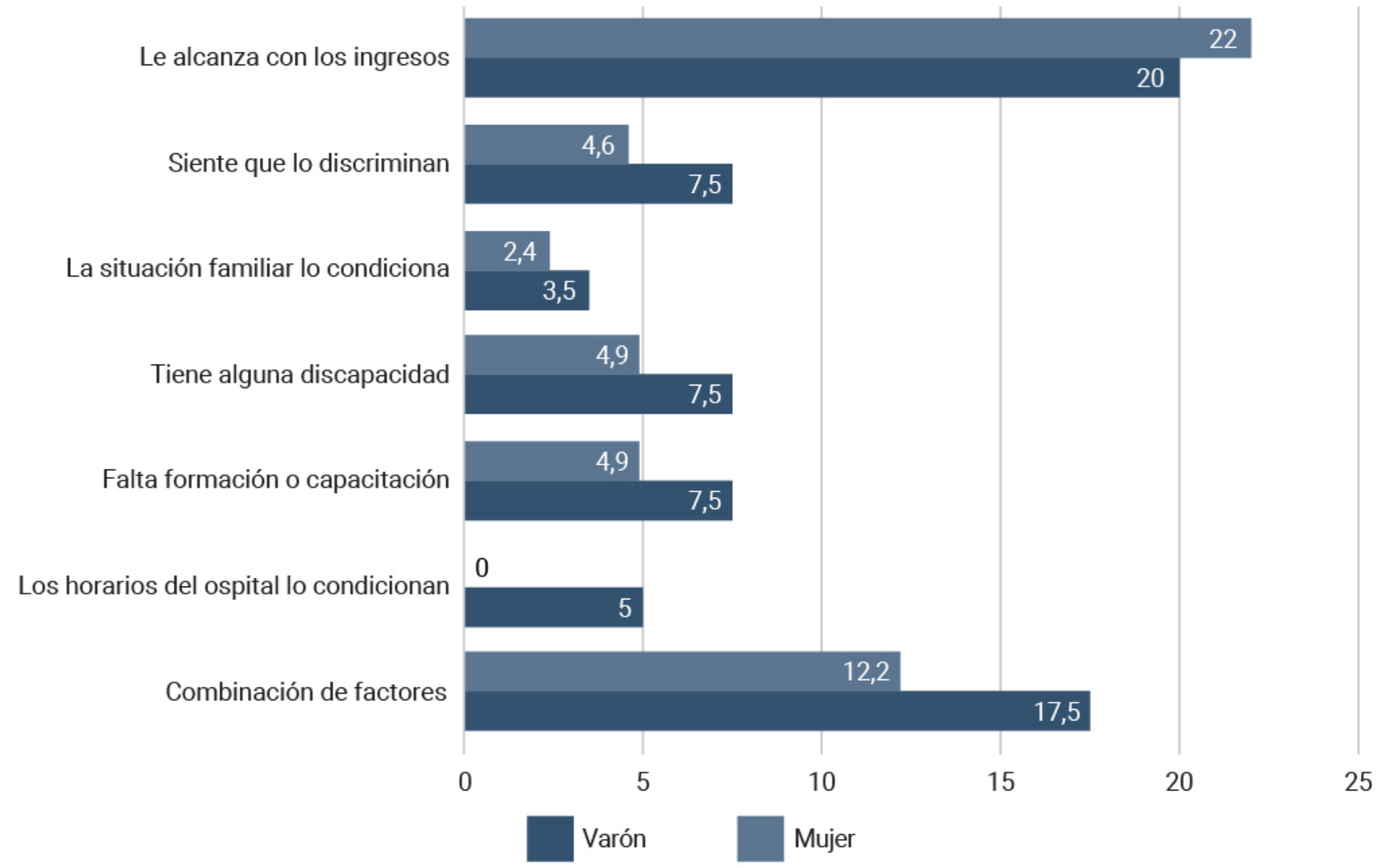

su composición: en la mayoría de las variables evaluadas no se encontraron diferencias significativas (rango de edad, tasa de carga viral indetectable, promedio de años viviendo con $\mathrm{VIH}$ y autopercepción de salud). Sí se observó que los hombres reciben menos beneficios sociales que las mujeres (43,9\% versus $20 \%, p=0,03$ ) debido a que estas últimas perciben con mayor frecuencia la AUH. Esto se evidencia en el porcentaje de personas a cargo que tienen (75\% las mujeres, $35 \%$ los hombres, $p=0,001$ ) y probablemente se relacione a su vez con el hallazgo de que las mujeres tienen menos oficios determinados que los hombres $(9,8 \%$ versus $27,5 \%, p=0,03)$.

Entre los hallazgos relevantes, uno de cada dos PVVIH cuenta con 7 o menos años de educación formal, pero solo un $7,5 \%$ de hombres y $4,9 \%$ de mujeres consideran que la falta de formación tiene alguna incidencia en el resultado de su búsqueda laboral.

Las mujeres que se encargan de los quehaceres domésticos autoperciben que ser "ama de casa" está visto como un trabajo a pesar de la no remuneración monetaria. Es claro que el tiempo invertido en el cuidado de la familia y los quehaceres domésticos se tradujo en la expansión del artículo sexto de la
Ley 25.994, con el Decreto 1454/2005, permitiendo a las amas de casa acceder al beneficio de la jubilación $(8,9)$.

Uno de cada cinco PVVIH en esta muestra considera que los ingresos que tienen les alcanzan para no tener que buscar trabajo. No obstante, aproximadamente seis de cada diez PVVIH subsiste con menos del valor del SMVM para el año 2015.

La brecha entre géneros también se observa: hay diferencias entre el dinero ganado por los hombres y las mujeres, aunque es mínima y estadísticamente no significativa; no obstante, se necesitan políticas de igualdad de género para equipararlo realmente. Es para recalcar, aun sabiendo que la muestra fue no probabilística, que la brecha hallada (5\%) fue menor al $34 \%$ publicado en la Argentina (5).

Desconocemos el motivo de la discapacidad que refieren las PVVIH de nuestra muestra, pero solo el 7,5\% de hombres y $4,6 \%$ de mujeres condiciona la búsqueda laboral a la misma.

Una de las limitaciones del estudio fue que la muestra para el mismo no fue probabilística, o sea que no conocemos con 
exactitud su verdadera representatividad. Pararealizarunanálisis más completo de la situación faltaría llevar a cabo un estudio de casos y controles con elección probabilística de la misma. Otra limitación es que este estudio se realizó en hospitales públicos de la provincia de Buenos Aires. Sumar PVVIH de lugares de atención privada aportará mayor representatividad a los resultados.

Este trabajo refleja una realidad invisible: las PVVIH atendidas en hospitales públicos bonaerenses ganan en promedio menos que el SMVM. El Estado no solo debe enfocar sus intereses en la prevención de nuevas infecciones y acceso al tratamiento, sino también en pensar políticas públicas e inclusivas para que las $\mathrm{PVVIH}$ puedan insertarse y mantenerse en el mundo laboral.

La situación económica del país ha ido cambiando en estos últimos años con crisis económicas marcadas. Sería necesario ver si la situación laboral de las PVVIH también lo hizo. 


\section{Referencias}

1. Padilla GV. Calidad de vida: Panorámica de investigaciones clínicas. Revista Colombiana de Psicología 2005; 13: 80-8.

2. Boletín sobre el $\mathrm{VIH}$, sida e ITS en la Argentina $\mathrm{N}^{\circ} 35$. Dirección de SIDA y ETS. Secretaría de Gobierno de Salud. Ministerio de Salud y Desarrollo Social Presidencia de la Nación. Argentina. Diciembre 2018.

3. Adaszko Ariel, Durán Adriana y Pacífico Natalia. Situación del acceso al diagnóstico oportuno, a los tratamientos y continuidad en la atención de las personas con VIH en la Argentina, 2014-2016, Dirección de Sida y ETS, Ministerio de Salud de la Nación, Buenos Aires. 2017.

4. Garrido PB, Paiva V, do Nascimento, VLV, Sousa JB, Santos NJS. Aids, estigma e desemprego: implicações para os serviços de saúde. Rev Saúde Pública 2007; 41(Supl. 2): 72-79.

5. RedLat. Trabajo decente en América Latina. Argentina. Edición 01- 2017. disponible en: http:// www.redlat.net/site/wp-content/uploads/2016/01/ Publica\%C3\%A7\%C3\%A3o-Nacional-Argentina-1.pdf visitado el 22 de noviembre de 2018.

6. Resolución 4/2015. Salario Mínimo, Vital y Móvil. Modificación. CONSEJO NACIONAL DEL EMPLEO, LA PRODUCTIVIDAD Y EL SALARIO MÍNIMO, VITAL Y MÓVIL. Disponible en: http://servicios.infoleg.gob.ar/ infoleglnternet/anexos/245000-249999/249538/norma. htm. Visitado el día 25 de noviembre de 2018.

7. International Labour office (ILO). The Impact of employment on HIV Treatment adherence., Geneva, Suiza. 2013.

8. Ley 25994/2004. Disponible en: https://www.argentina. gob.ar/normativa/nacional/ley-25994-102726. Acceso: 30 de septiembre de 2020.

9. Decreto 1454/2005. Disponible en http://servicios.infoleg. gob.ar/infolegInternet/anexos/110000-114999/111942/ norma.htm. Acceso 30 de septiembre de 2020. 
Employment of people living with HIV in the province of Buenos Aires

One of the variables to measure the quality of life of people living with the Human Immunodeficiency Virus (HIV) is labour. The objective was to compare the labour situation of people living with the HIV in Buenos Aires discriminating by gender. Comparative study in 3 hospitals between April and July 2015. The following were evaluated: age range, idg, antiretroviral treatment, viral load, dependents, self-perception of health status, educational level, work situation, access to social benefits, comparison between income and minimum wage, occupation. $a=5 \%$ to two queues. Mann-Whitney-Wilcoxon and Fisher tests were conducted. 82 surveys were performed. $87.2 \%$ between 20 and 59 years old; male $(M) /$ female $(F)$ ratio: $1 / 1 ; 84.1 \%$ under antiretroviral treatment and $67.1 \% \mathrm{had}$ undetectable viral load. $54.9 \%$ with dependents. The median self-perception of health was 7.94 with no differences between sexes ( $p=0.35)$. $48.8 \%$ of the $M$ and $50 \%$ of the $F$ had at most 7 years of formal education. $17.1 \%$ of the men and $7.5 \%$ of the women were unemployed $(\mathrm{p}=0.03)$; informal work accounted for $65.8 \%$ of the men and $37.5 \%$ of the women, but $47.5 \%$ of the women were housewives. $32.9 \%$ of the people do not receive social benefits, $20 \%$ of $F$ and $43.9 \%$ of $M(p=0.03)$. The income of the people corresponded to $64.8 \%$ of the minimum wage. The economic situation of the country has changed, and it remains to be seen if the employment situation has changed as well.

Keywords: Employment. HIV, Gender inequality. 